\title{
COSTES LEGALES Y HONORARIOS DE ABOGADOS EN EL PROCESO CIVIL Observaciones sobre la situación en los Estados Unidos y en Europa
}

\author{
Goretti Vadillo Robredo
}

\begin{abstract}
Sumario: I. Introducción. II. American Rule. 1. Introducción. 2. Excepciones. 3. Argumentos a favor y en contra de la regla americana. III. Pacto de cuota litis o contingent fee. Reformas del Derecho de tort norteamericano. IV. Análisis de la situación en Europa. 1. Reglas europeas. 2. Situación en Europa de los contingent fees. 3. Algunos supuestos concretos (en particular, procesos civiles de reclamación de daños a la persona). V. Postura del análisis económico del derecho. VI. Reformas.
\end{abstract}

\section{INTRODUCCION}

Las normas que regulan los costes legales y los honorarios de los abogados varían entre los países; no sólo en Europa sino también en los Estados Unidos. En la actualidad existe la creencia de que en Norteamérica se da un frecuente y sistemático abuso del proceso judicial, un exceso de demandas «no meritorias».

En los Estados Unidos gobierna la «regla americana» según la cual cada parte en el proceso corre a cargo de sus costes legales, junto con la aceptación total de los acuerdos de cuota litis. En Europa, de forma general, rige la regla «el perdedor paga», y los acuerdos de cuota litis, en muchos países, o están prohibidos o no se consideran éticos.

Resulta muy difícil, si no casi imposible, llegar a una conclusión firme sobre si la diferencia entre las reglas europeas y norteamericanas, en relación a los costes legales, tiene efecto en la congestión y en los retrasos de los tribunales. Sin embargo, un sector importante de la doctrina norteamericana apunta a que la existencia de estas prácticas son culpables, en cierta medida, de la obstrucción de los tribunales con demandas «no meritorias». 
En este artículo analizaremos las reglas que se aplican en los Estados Unidos, ya que es aquí donde encontramos las diferencias más notables y donde, tanto la doctrina como la jurisprudencia se plantean desde hace dos décadas la posibilidad de sustituir su sistema por otro cercano al europeo.

\section{AMERICAN RULE}

\section{Introducción ${ }^{1}$}

Según la «regla americana» cada parte en el proceso —en ausencia de un contrato o de una ley que indique lo contrario, o de circunstancias extraordinarias - es responsable de los honorarios de su abogado, gane o pierda el pleito. Los Estados Unidos son casi la única democracia industrializada que mantiene esta práctica $^{2}$. En la mayoría de los países, incluida Inglaterra, el ganador - demandante o demandadotiene derecho a que le sean indemnizados sus gastos legales por el perdedor, incluyendo los honorarios de su abogado ${ }^{3}$.

Durante el período colonial de los Estados Unidos, los honorarios de los letrados se regulaban por ley. Su propósito era el de prescribir tanto los honorarios de los abogados para con sus clientes, como aquellos que podían ser reclamados a la parte perdedora. Esta práctica provenía de Inglaterra, pero la diferencia entre ambos países se encontraba en que las escalas inglesas no se establecían por ley, sino por la costumbre. Parece que los primeros tribunales de la colonia norteamericana indemnizaban todos los costes de forma rutinaria, incluyendo los honorarios de los abogados, al litigante con éxito ${ }^{4}$. Una explicación

1 Este nombre ha sido atribuido a Goohart, A.L., «Costs», en Yale Law Journal, vol. 37, 1929, pp. 849-878.

El único estado norteamericano que ha adoptado la regla europea de indemnizar los honorarios de los abogados es Alaska; ver NotE, «Award of Attorney's Fees in Alaska» en UCLA-Alaska Law Review, vol. 4, 1974, pp. 129 y ss.

2 Japón sigue la regla americana, aunque contiene la importante excepción de indemnizar los honorarios del demandante ganador en los casos de tort. Ver KoJIMA y TANIGUCHI, Access to Justice in Japan, en Cappelleti y Garth (eds), 1978, Access to Justice, vol. 1, pp. 704-705.

3 Ver Pfennigstorf, W., «The European Experience with Attorney Fee Shifting», en Law and Contemporary Problems, vol. 47, 1984, p. 37.

4 Ver, por ejemplo, Evrell v. Bradstret, 3 Records of the Court of Assistants, Colony of the Massachusetts Bay 163 (1666) (publicado en 1928); Clarke v. Davis, en 130 (1662); Hakins v. Gooden en 163 (1660). 
ofrecida para el abandono de esta práctica fue el rápido desarrollo de un ambiente de hostilidad y desconfianza hacia los profesionales del Derecho.

El Profesor Ehrenzweig ${ }^{5}$ ha sugerido que el alejamiento americano de la práctica inglesa de honorarios pudo haber ocurrido por otro tipo de causas:

«De hecho, existen buenas razones para asumir que lo que ahora es entendido como un postulado notable es debido al simple hecho de que el Parlamento de Nueva York, en $1848^{6}$, en un intento de perpetuar lo que se consideraba una buena regla legal de recobrar los honorarios por la parte ganadora, cometió el error fatal de fijar la cantidad percibible en dólares y centavos en lugar de un porcentaje de la cantidad indemnizada. Fue este error probablemente el que causó que los tribunales y los abogados, cuando creció el coste de la vida, oscureciesen el propósito real de la cantidad legal de "costes", olvidando gradualmente el significado de esas cantidades» ${ }^{7}$.

En opinión de Goohart ${ }^{8}$, si el Código de Nueva York de 1829, en lugar de establecer un honorario fijado para cada caso, hubiera permitido a la parte con éxito la indemnización de unos honorarios razonables, dependiendo de la naturaleza del proceso, el sistema se habría desarrollado según las líneas del Derecho inglés. Para el profesor Fleming ${ }^{9}$, tal vez debido a un origen y naturaleza erróneos, la regla fue aceptada sin que se diera ningún intento de explicación.

La primera declaración del Tribunal Supremo de los Estados Unidos sobre este tema es la de Arcambel $v$. Wiseman ${ }^{10}$, y en ella se negó el argumento de que los honorarios de los abogados deberían ser incluidos en la indemnización como un ítem legítimo y necesario para compensar a la víctima por todos sus daños legales ${ }^{11}$. En 1851, el Tribunal Supremo en Day v. Woodworth ${ }^{12}$ de nuevo negó la posibilidad de considerar los honorarios de los abogados como ítem compensatorio. En

5 EhrnzweIG, A.A., «Reimbursement of Counsel Fees and the Great Society», en California Law Review, vol. 54, 1966, pp. 792-800.

6 1848, NY Laws 258.

7 EhrenZweig, «Reimbursement of Counsel Fees...» cit., p. 799.

8 Goohart, «Costs...» cit., p. 875.

9 Fleming, J.G., The American Tort Process, Clarendon Press, Oxford, 1988, p. 189.

103 U.S. (3 Dall) 306 (1796).

113 U.S. (3 Dall) 306 (1796):

«The general practice in the United States is in oposition to (the allowance of attorney's fee) (...) and even if that practice were not strictly correct in principle, it is entitled to the respect of the court, till it is changed, or modified, by statute».

1254 U.S. (13 How) 363 (1851). 
$1872^{13}$, aunque se continuaba citando los casos anteriores, el Tribunal, por primera vez, justificó la aplicación de la regla americana en el miedo a que las partes soliciten más asesoramiento del necesario y a que los abogados demanden unos honorarios mayores que los que habrían reclamado a su cliente. Seis años después, el Tribunal de nuevo trató directamente la cuestión de los honorarios ${ }^{14}$. La defensa de la regla americana, en este caso, fue distinta, ya que propuso que los honorarios no podían ser incluidos como parte de la indemnización, porque no eran causa próxima de la acción del demandado; es decir, no eran previsibles.

\section{Excepciones}

El descontento de ciertos sectores de la población hacia la aplicación de la regla general se ha plasmado en distintas leyes: la Voting Rights de 1870, la Interstate Commerce Act de 1887, la Sherman AntiTrust Act de 1890, la Security Act de $1933^{15}$, la Consumer Product Safety Act de $1976^{16}$, la Copyright $A c t^{17}$ y más de 70 leyes federales ${ }^{18}$. Este movimiento contrario a la regla americana se ha acelerado en las últimas décadas, tanto a nivel estatal como federal ${ }^{19}$.

Judicialmente se han creado dos excepciones basadas en el interés público: son las excepciones de obduracy (obstinación, terquedad) y la de «common fund». La primera, en interés de la eficiencia judicial, per-

13 Ver Oelrichs v. Spain, 82 U. S. (15 Wall ) 211, 230 (1872).

14 Stewar v. Sonneborn, 98 U.S. 187 (1878).

1515 U.S.C. $77 \mathrm{k}(\mathrm{e})(1976)$.

1615 U.S.C. 2059(e) (4) (1976).

1717 U.S.C. 565 (1976).

18 Ver Note, «Promoting the Vindication of Civil Rights Through the Attorney's fees award Act», en Columbia Law Review, vol. 80, 1980, p. 346.

19 Ver, entre otros:

Los casos de antitrust (15 U.S.C. 15 (1970)), la Comunications Act (47 U.S.C. 206 (1970)), la violación de leyes de Copyright (17 U.S.C. 116 (1970), la Fair Labor Standards Act (29 U.S.C. 216 (b)(1970)), ciertas violaciones de comercio interestatal (49 U.S.C. 8, 908(b)(1970)), bajo la Merchant Marine Act (46 U.S.C. 1227(1970)), casos de la Packers and Stockyards Act (7 U.S.C. 210(f) (1970)), bajo las leyes de patentes (35 U.S.C. 285 (1970)), bajo la Perishable Agricultural Commodities Act (7 U.S.C 499g(b) (1970)), bajo la Railway Labor Act (45 U.S.C. 153(p)(1970)), por violaciones de la Securities Exchange Act (15 U.S.C. 78i(e), 78r(a) (1970)), bajo la Servicement's Readjustment Act (38 U.S.C. 1822(b) (1970)), y la Trust Indenture Act (15 U.S.C. 77w(a) (1970)).

Ver Note, «State Attorney Fee shifting Statutes: are we quietly Repealing the American Rule?», en Law \& Contemporary Problems, vol. 47, 1984, p. 321. 
mite al litigante con éxito recobrar los costes legales de un adversario culpable de «obstinación», antes o durante el juicio. Sin embargo, la excepción mejor establecida es la conocida como el «common fund», que «(...) creció por el poder histórico de la equidad para permitir que la parte que preserva un fondo común para el beneficio de otros como para sí mismo recobre sus costes, incluidos los honorarios de los abogados (bien extrayéndolos del fondo o de la propiedad misma, o directamente de las otras partes que se benefician) $»^{20}$. Esta doctrina creada judicialmente es muy importante para financiar la «class action» ${ }^{21}$, en la cual uno o varios demandantes representan a una clase compuesta por muchos demandantes. Algunos tribunales norteamericanos ${ }^{22}$ han considerado que es injusto imponer al representante de una clase, el cual ha trabajado para otros y para sí mismo, unos honorarios de abogados de los cuales se han beneficiado otros, los cuales además no han incurrido en gasto alguno. Por último, los tribunales han considerado que en aquellos casos en los que el litigante contrario ha actuado con completa mala fe no se debe aplicar la regla americana, y por lo tanto indemnizan al litigante de buena fe sus costes legales ${ }^{23}$. Este argumento, como luego veremos, también lo encontramos en países europeos.

En Alyeska Pipeline Service Co. v. Wilderness Society ${ }^{24}$ el Tribunal Supremo redefinió la american rule declarándose en contra de indemnizar los honorarios de los abogados a las partes ganadoras en casos

20 Alyeska Pipeline Service v. Wilderness Society, 421 U.S. 240, 257 (1975).

21 «Class action» hace referencia a las acciones de grupo en las que se hacen valer individualmente intereses compartidos por varios sujetos, por ejemplo en materia ambiental; acción popular.

22 Algunos casos representativos son:

Trustes v. Greenpugh, 105 U.S. 527 (1881); Central R.R. \& Banking Co. v. Pettus, 113 U.S. 116 (1885); Sprague v. Ticonic Nat'l Bank, 307 U.S. 161 (1939).

Ver, Dawson, «Lawyers and Involuntary Clients: Attorney Fees from Funds», en Harvard Law Review, vol. 87, 1974, p. 1.597.

23 Ver:

Vaughan v. Atkinson, 369 U.S. 527 (1962); Toleo Scale Co. v. Computing Scale Co., 261 U.S. 399 (1923); Bell v. School B., 321 F.2d 494 (4th Cir. 1963); Universal Oil Prods. Co. v. Root Ref. Co. 328 U.S. 575, 580 (1946); Guardian Trust Co. Kansas C.S. Ry., 28 F.2d 233, 246 (8th Cir. 1928).

Esta excepción ha sido parcialmente codificada en el Federal Review Civil Procedure 37(b), (c) la cual permite a los tribunales imponer los honorarios de los abogados a la parte que no ha cooperado en las pruebas; Federal Review Civil Procedure, 41(d); la Federal Review App. Procedure 38 que indemniza los honorarios como parte de los costes en contra de la parte que apela con una apelación «frívola».

24421 U.S. 240 (1975). 
que no supongan ninguna de las tres excepciones reconocidas por la jurisprudencia ${ }^{25}$. Especialmente, el tribunal estuvo en contra de la excepción conocida como el «private attorney general». La razón alegada para la negativa se basaba en que la judicatura, con la creación de esa excepción a la regla general de la american rule, estaba «invadiendo el ámbito de la legislatura» ${ }^{26}$.

Cuando las jurisdicciones norteamericanas se han separado de la regla general no han adoptado la regla «el perdedor paga». La intención de los parlamentos y de los tribunales ha sido la de proveer una indemnización de honorarios para los demandantes si éstos ganan, pero no a los demandados. Usualmente, esas provisiones han sido «one-way» es decir, leyes que sólo favorecen al demandante vencedor (una excepción es el Equal Access to Justice Act que indemniza los honorarios a ambas partes ${ }^{27}$ ). La razón aparente para estas leyes de «one-way» es la de incentivar a las víctimas para que actúen como «fiscales privados» ${ }^{28}$ o la de ajustar el desequilibrio entre los recursos de las partes ${ }^{29}$.

Como resumen, podemos decir que en la actualidad existen cuatro supuestos en los que la indemnización al demandante de los honorarios de su abogado es la regla general: 1) cuando se aplica la doctrina del fondo común, 2) cuando ha habido mala conducta o mala fe en la conducta del demandado, 3) cuando una ley lo autoriza, 4) cuando existe un contrato válido entre las partes que lo autorice.

25421 U.S. 240 (1975), pp. 257-59.

Las tres excepciones son las comentadas anteriormente: a) mala fe de una de las partes, b) la doctrina del «fondo común», c) la doctrina de obduracy.

26421 U.S en 271. El Congreso reaccionó aprobando la Civil Rights Attorney's Fees Awards Act de 1976 (Pub.L.No. 94-559, 90 Stat 2641 (1976) (Codificada en 42 U.S.C. 1988 (1976)). La Ley contiene la sección 1988 del título 42 que permite la indemnización de los honorarios de los abogados a las partes ganadoras en aquellas demandas que tratan de poner en práctica el United States International Revenue Code o el título VI de la Act of Civil Rights de 1964. Los tribunales han llegado al acuerdo general de que el estándar de discreción de la sección 1988 para indemnizar los honorarios es el mismo que gobierna en provisiones legales similares de honorarios: la parte ganadora «deberá ordinariamente recobrar los honorarios de abogados a menos que circunstancias especiales conviertan a la indemnización en injusta». Ver Newman v. Piggie Park Enterprises, Inc., 390 U.S. 400, 402 (1968).

27 Equal Acces to Justice Act, Pub. L. No. 96-481, 94 Stat. 2325 (codificado en las secciones del título 5, 15, 28 y 42 del U.S.C.).

${ }^{28}$ Como se establece en la Civil Rights Attorneys' Fees Awards Act, 42 U.S.C. 1988 (1988).

29 Ver la Fair Labor Standards Act, 29 U.S.C. 206-207, 216(b) (1988). 


\section{Argumentos a favor y en contra de la regla americana}

Comúnmente se alega que la american rule fracasa en su intento por lograr uno de los principales objetivos del Derecho de daños: la compensación total de los daños sufridos. Se ha dicho que la indemnización de los honorarios (y otros costes razonables del proceso) es necesaria para proporcionar una compensación adecuada por las pérdidas económicas reales, así como para lograr la disuasión de comportamientos inaceptables ${ }^{30}$. El fin de asegurar que la víctima recibe una compensación total por, al menos, el neto de sus pérdidas económicas requiere una indemnización que cubra los costes legales. En otras palabras, un Derecho que ignore el coste real de la lesión estará lejos de proveer un consuelo total por el daño sufrido.

Parece claro que desde el punto de vista de la indemnización, las facturas legales son un candidato a la compensación tan legítimo como, por ejemplo, las facturas médicas.

La objeción tradicional alegada contra la adopción de un sistema similar al europeo («el perdedor paga») está basada en la visión de que el Derecho, en cierta medida, es una especie de juego, y por lo tanto es injusto penalizar a la parte perdedora. Se alega que es «injusto golpear a un hombre que está caído» y reclamar costes en contra de una persona que ha perdido en el proceso parece algo similar ${ }^{31}$.

El profesor Ehrensweig dijo que cuando discute con sus colegas la adopción de un sistema distinto del americano ellos invariablemente le contestan:

«Es suficientemente malo ver a alguien que ha perdido, el cual en justicia debería haber prevalecido. Hacer que pague los honorarios de la parte ganadora añadiría injusticia a la injusticia, supondría golpear a una persona, y haría que el hombre modesto no acudiese a los tribunales, tanto si es el demandado como el demandante» ${ }^{32}$.

30 Hay que tener en cuenta que la generosidad tradicional de los jurados con la collateral source rule, los daños punitivos y la compensación por pain and suffering normalmente ha sido explicada y justificada como una forma de compensar la injusticia implícita de negar compensación por los necesarios honorarios de los abogados.

31 Este argumento lo recoge SATTERWAITE, «Increasing Costs to be Paid by a Losing Party», en New Jersey Law Journal, vol. 46, 1923, p. 133:

«El sistema aducido (el perdedor paga todos los costes) está basado en la asunción totalmente infundada de que la parte perdedora en el proceso es siempre, u ordinariamente, la parte equivocada. Su única justificación debe estar en que un veredicto adverso o una decisión desfavorable del tribunal acarrea la necesaria conclusión de que la parte perdedora era moralmente culpable por entablar la acción, o por contestar a la demanda. Nada de esto se puede extraer de los hechos reales de la vida (...)».

32 Ehrensweig, A.A., «Reimbursement of Counsel Fees and the Great Society...», cit., p. 796 . 
En su opinión, este argumento es claramente incorrecto:

«(...) ¿qué es esto de creer que los jueces se equivocan más de lo que aciertan? Como ha dicho el juez Goohart en respuesta a este argumento "Si la justicia en New Jersey es una cuestión de suerte, no parece que sea necesario tener tribunales y abogados. Sería más barato, y ciertamente menos dilatorio, tirar una moneda al aire"».

Una segunda crítica citada comúnmente es que la american rule no provee de incentivos suficientes para la disuasión de conductas ilícitas. Es decir, para que un agente ilícito se vea incentivado a adoptar las medidas de cuidado necesarias debe de correr con todos los gastos ocasionados por su actuar descuidado. Sin embargo, el análisis del efecto disuasorio de la american rule y el de la regla «el que pierde paga» es mucho más complicado de lo que a primera vista pudiera parecer, y no se han aportado datos empíricos por la doctrina norteamericana sobre esta cuestión ${ }^{33}$.

A favor del sistema americano se dice que evita muchas barreras de acceso a la justicia y promueve la negociación extrajudicial entre las partes. En los Estados Unidos existe la creencia de que un sistema similar al europeo es antidemocrático porque desincentiva a la clase más pobre, favoreciendo a los que poseen mayores recursos financieros ${ }^{34}$. El estudio realizado por el American Law Institute llegó a la conclusión de que la regla «el perdedor paga» crea una importante falta de incentivos en la persecución de demandas meritorias pero no claramente vencedoras, sobre todo en los casos en los que las víctimas son adversas al riesgo (por ejemplo, demandantes de clase media con algo que perder pero sin muchos recursos para afrontar la pérdida). Además, consideran que la regla americana proporciona un incentivo para que las partes lleguen a un acuerdo extrajudicial con rapidez y ahorren costes futuros ${ }^{35}$.

33 American Law InSTITUTE, American Law Institute's Reporters' Study on Enterprise Responsibility for Personal Injury, Philadelphia, 1991, pp. 267 y ss. El informe del American Law Institute hace referencia al efecto disuasorio pere no dice nada concreto, sólo apunta la posibilidad.

34 Ver Fleming, The American Tort Process... cit., p. 193.

35 Son de esta opinión el American Law Institute, The American Law Institute's Reporters' Study on Enterprise Responsability for Personal Injury... cit., p. 280 y LeubsDorf, «Recovering Attorney fees as Damages», en Rutgers Law Review, vol. 38, 1986, pp. 456-57.

El argumento contrario: la regla «el perdedor paga» dará lugar a un mayor número de acuerdos extrajudiciales porque crea mayores costes legales y con ello hace que «existan mayores ganancias potenciales si se alcanza un acuerdo antes de llegar al tribunal» lo encontramos en HAUSE, «Indemnity Settlement, and Litigation, or "I'll Be Suing You"», en Journal of Legal Studies, vol. 18, 1989, pp. 157-58 y HERSCH, «Indemnity, Settlement, and Litigation: Comment and Extension», en Journal of Legal Studies, vol. 19, 1990, p. 235. 
Sin embargo, la creencia de que la abolición de la regla americana daría lugar a un sistema antidemocrático fue desmentida por el juez Goohart ya en $1929^{36}$. Según este autor, la experiencia inglesa ha demostrado que es el demandado rico quien más sufre bajo este sistema, puesto que si pierde tendrá que abonar los costes legales de la víctima, mientras que si gana no será capaz de recibir sus propios costes de un adversario sin recursos ${ }^{37}$.

Fleming ${ }^{38}$ señala que la adopción de una regla similar a la europea proporciona un incentivo y un desincentivo para el litigante de clase media: ofrece la posibilidad de no tener que recurrir a su propia indemnización para abonar los honorarios de los abogados, pero el riesgo de perder es considerablemente mayor por la responsabilidad potencial de abonar los honorarios de la otra parte. En su opinión, el efecto neto de esta combinación es incierto, pero parece más probable que desincentive las demandas y defensas de este grupo de litigantes, porque la aversión al riesgo es probablemente mayor entre los de renta media, mientras que los de renta alta y litigantes frecuentes tienden a ser neutrales al riesgo.

En un extenso artículo publicado por la Universidad de Pennsylvania $^{39}$ se llegó a la conclusión de que la regla europea incentiva a que una persona con una demanda justa, pero sin gran poder económico, la interponga. La práctica actual tiende a disuadir la persecución de demandas pequeñas pero claramente meritorias para aquellos litigantes que pueden resultar indemnizados con una cantidad menor a la de los honorarios de su abogado. Para los demandados, el costo de defenderse en contra de una demanda injusta y pequeña puede exceder fácilmente al coste de pagar simplemente lo que se le demanda. Sin embargo, el abandono de la regla americana incentivará la defensa de derechos legales claros con una alta probabilidad de éxito, pero añadirá un nuevo factor al elemento disuasorio del Derecho presente en los casos en los que la demanda es nueva. Es probable que las personas con pocos recursos económicos tengan miedo a la posibilidad de pagar ambos hono-

36 Goohar, A.L., «Costs...», cit., p. 875.

37 En apoyo de esta postura ver también a Note, «Promoting the Vindication of Civil Rights Through the Attorney's Fees Awards Act», en Columbia Law Review, vol. 80, 1980; TunNEY, «Financing the Cost of Enforcing Legal Rights», en University of Pennsylvania Law Review, vol. 122, 1974, p. 632; Note, «Fee simple: a Proposal to Adopt a Two-way Fee Shift for Low-Income litigants», en Harvard Law Review, vol. 101, 1988.

38 Fleming, The American Tort Process... cit., p. 194.

39 Comment, «Courts Awarded Attorney's Fees and Equal Acces to the Courts», en University of Pennsylvania Law Review, vol. 122, 1974, pp. 636 y ss. 
rarios y se vean más disuadidas por ello que los que poseen recursos económicos. Además, estos autores consideran que es probable que este grupo de litigantes (los de baja renta) sean manipulados en las negociaciones prematuras.

Ehrenzweig ${ }^{40}$ tampoco comparte la idea de que la abolición de la regla americana dará lugar a un sistema antidemocrático. Considera que ésta es una posibilidad improbable, y que además el Derecho se verá beneficiado con la adopción de la regla «el perdedor paga», ya que disuadirá a un gran número de demandantes sin causa, puesto que con la norma actual sólo se enfrentan a sus propios gastos legales, mientras que con la abolición de la regla tradicional el riesgo en caso de pérdida de la demanda será mayor ${ }^{41}$.

En defensa de la regla americana encontramos declaraciones del Tribunal Supremo de los Estados Unidos ${ }^{42}$ :

«Como soporte de la american rule se ha argumentado que debido a que los procesos judiciales son al menos inciertos, uno no debería ser penalizado por defender o plantear una demanda, y que el pobre puede resultar injustamente desincentivado para entablar una acción si la pena de perder incluye los honorarios del abogado de su oponente (...). También el tiempo, los gastos, y las dificultades de prueba inherentes a la valoración de los honorarios de abogado supondrá unas cargas importantes para la Administración de Justicia».

Como hace el Tribunal Supremo, algunos autores han defendido la regla americana en base a que reduce los costes de la Administración de Justicia. La demanda de honorarios parece ser un coste inevitable de la norma «el perdedor paga». También se ha dicho que otorgar a los jueces un amplio poder discrecional en la indemnización de los honorarios es contrario a la «concepción general norteamericana de una judicatura atada por reglas fijadas» ${ }^{43}$, la cual parece totalmente incorrecta porque el sistema judicial está repleto de ejemplos de discreción judicial.

Es evidente que las justificaciones para la american rule no sólo no son uniformes sino que además han perdido gran parte de su peso con

40 Ehrenzweig, «Reimbursement of Counsel Fees an the Great Society...», cit., p. 796.

41 Parece claro lo que sugirió el MassachusetTs Judicial Council, «First Report of the Judicial Council of Massachusetts», en Massachusetts Law Quarterly, vol. 11, 1925, p. 63: «(...) la posibilidad de tener que pagar las facturas de los abogados de las dos partes en la acción, hace que el demandante se piense dos veces antes de demandar sin tener derecho y que el demandado se lo piense dos veces antes de defenderse de la acción que no debería ser defendida».

${ }^{42}$ Fleischmann Corp. v. Maier Brewing Co., 368 U.S. 714, 718 (1967).

43 Goohart, A.L., «Cost...», cit., p. 877. 
el paso del tiempo. En la actualidad, existen tantos argumentos a favor como en contra si se analiza esta norma de forma aislada. Aunque, debido a las reformas que han tenido lugar en otras normas del Derecho de daños ( Collateral Source Rule», daños punitivos, "pain and suffering», etc.), la doctrina norteamericana se ha visto forzada a buscar nuevas alternativas, que luego trataremos.

\section{PACTO DE CUOTA LITIS O CONTINGENT FEE}

Los acuerdos de contingent fees son conocidos en España como el pacto de cuota litis. Se ha dicho que una de las principales ventajas de la american rule son los acuerdos de contingent fee. La base de estos acuerdos es sencilla: el abogado y el demandante se ponen de acuerdo en que los honorarios del primero serán un porcentaje de la indemnización recibida por la víctima (el porcentaje depende del tipo de proceso o del estadio: negociación, juicio, apelación) ${ }^{44}$. En Europa, incluso en Inglaterra, este tipo de acuerdos entre abogados y clientes no se consideran éticos y en algunos países se consideran ilegales ${ }^{45}$.

El especial acuerdo de contingent fee entre la víctima y su abogado libera al demandante de los gastos de su abogado si pierde; es decir, traslada el riesgo de la pérdida de sí mismo a su abogado. Se considera que ésta es la razón por la que el demandante tiene que pagar un precio (o, mejor dicho, una prima) sobre el honorario si es que su abogado tiene éxito (normalmente una tercera parte de la indemnización).

La justificación principal aportada por la doctrina y jurisprudencia norteamericana para los contingent fees es que proporcionan un fácil acceso a la justicia para los demandantes sin tener en cuenta sus fuentes financieras. El contingent fee evita cualquier efecto disuasorio que pudiese tener en el demandante el hecho de correr con los gastos de su abogado en caso de perder la demanda. Sin embargo, se critica que esta situación privilegiada del demandante norteamericano tiene un precio,

44 Ver McKinnon, «Contingent Fees for Legal Services», en A Report of the American Bar Foundation, 1964.

${ }^{45}$ Ver, por ejemplo:

Inglaterra: Solicitors Act 1974, s.59(2)(b); Wallersteiner v. Moir (No.2), (1975) QB 373(C.A).

Alemania: BGHZ 22, 162 (1965); BGHZ 44, 183 (1965).

El acuerdo de contingent fees es aceptado en Canadá, ver WiLlinston, «The Contingence Fee in Canada», en Albany Law Review, vol. 6, 1968, pp. 184 y ss.; KRITZER, «Fee arrengements and Fee Shifting: Lessons from the Experience in Ontario», en Law and Contemporary Problems, vol. 47, 1984, pp. 125 y ss. 
ya que en el supuesto de que la demanda tenga éxito, los honorarios del abogado serán mayores - que si se hubiesen calculado sobre otras bases- y deberán ser extraídos de la indemnización.

La cuestión principal para el abogado norteamericano, en opinión del profesor Fleming ${ }^{46}$ es si el caso vale lo suficiente como para aceptar el riesgo. El abogado calculará lo que vale el caso: por ejemplo, la cantidad probable que se concederá como indemnización descontando la posibilidad del fracaso. Cuanto más grande sea la indemnización, mayor será su recompensa. Fleming llega a la conclusión de que, en términos prácticos, cuanto mayor sea, por ejemplo la lesión, más probable será que la víctima encuentre un abogado para su caso ${ }^{47}$.

De todas formas, los acuerdos de cuota litis no están reservados a las víctimas o clientes de baja renta, puesto que la mayoría de los abogados prefieren ofrecer sus servicios en bases contingentes sin tener en cuenta las fuentes financieras del cliente (presumiblemente porque el honorario es mayor que si cobrase por horas $)^{48}$.

El contingent fee ha sido criticado con frecuencia por que se considera que supone un regalo desproporcionado para el abogado ${ }^{49}$. Aunque los términos del contrato no son uniformes, la media suele suponer un honorario del $33,3 \%{ }^{50}$. La atención pública inevitablemente se fija en las indemnizaciones multimillonarias en las que los honorarios parecen excesivos ${ }^{51}$. Sin embargo, en la mayoría de los veredictos o negociaciones extrajudiciales la indemnización es mucho más modesta. De hecho, los costes legales de los demandados y demandantes no son tan distintos; al menos en los casos rutinarios, los abogados de las víctimas no ganan mucho más que sus adversarios con salarios establecidos según las horas de trabajo.

46 Fleming, The American Tort Process... cit., p. 197.

47 Fleming, The American Tort Process... cit., p. 198.

48 El American Bar Association Model Code of Professional Responsibility EC-2 establecía que «un abogado debe rechazar un caso basado en un acuerdo de honorarios contingentes si el cliente tiene capacidad para abonar un honorario fijo razonable». Las ABA Model Rules of Professional Conduct (Rule 1.5) de 1981 ya no contienen esta norma.

49 Ver, por ejemplo LeubSDORF, «The Contingency Factor in Attorney Fee Awards», en Yale Law Journal, vol. 90, 1981, p. 473.

50 Algunos acuerdos establecen un incremento en la escala dependiendo del lugar en el que termina el proceso, por ejemplo un $25 \%$ si el caso se negocia antes de entablar la demanda o un $50 \%$ en apelación. Otros proveen escalas separadas para tipos específicos de demandas.

51 Según el Wall Street Journal del 9 de diciembre de 1985, los abogados de las víctimas de asbestosis recibieron un billón de dólares norteamericanos como consecuencia del acuerdo realizado con Manville Corporation. 
En teoría, el supuesto «regalo» ocasional se justifica como una compensación retrasada por los casos sin éxito. Las víctimas o los demandantes, como clase, parece que también prefieren no tener que pagar por los honorarios si pierden, aunque tengan que pagar más si ganan.

En opinión del profesor Fleming ${ }^{52}$, el riesgo de estos acuerdos puede estar en que los abogados se dediquen casi exclusivamente a casos con una alta indemnización y altas posibilidades de ganar y nieguen sus servicios a otros con demandas meritorias pero sin grandes indemnizaciones. Sin embargo, para este autor el problema no es grave pues hay que tener en cuenta que éste es un campo en el que existe una alta competencia entre los abogados.

Finalmente, se han criticado los efectos adversos del contingent fee en el proceso judicial ${ }^{53}$. Se dice que incentivan de forma excesiva y poco profesional la conducta del abogado de «ganar a toda costa». Otro reproche es que estos acuerdos incentivan las demandas no meritorias, agravando el atasco y los retrasos en los tribunales. Pero, para Fleming ${ }^{54}$, el honorario establecido según las horas de trabajo parece ofrecer un mayor incentivo para esta forma de abuso.

\section{Reformas del Derecho de tort norteamericano}

La regla americana y los contingent fees han tenido un efecto importante en el desarrollo de la doctrina jurídica norteamericana. La generosidad tradicional de los jurados en el cálculo de la indemnización ha sido explicada y justificada como una forma de remediar la injusticia implícita de negar compensación por los costes legales (en especial, los honorarios de los abogados).

En las últimas dos décadas, en los Estados Unidos, ha tenido lugar un movimiento de reforma del Derecho de daños inspirado, en parte, en limitar el quantum de las indemnizaciones y restringir el acceso de las demandas a los tribunales. Como resultado de la actividad legislativa y judicial de reforma los parlamentos estatales y los tribunales se han visto forzados a considerar los efectos que las nuevas leyes tienen sobre la regla americana y los contingent fees.

La american rule ha dado lugar a que en la práctica la víctima busque en la indemnización de daños de "pain and suffering» (similares a los daños morales o daños extrapatrimoniales) no sólo la forma de ser

52 Fleming, The American Tort Process... cit., p. 200.

53 Ver McKinnon, «Continge Fees for Legal Services», en A Report of the American Bar Foundation, 1964.

54 Fleming, The American Tort Process... cit., p. 203. 
compensado por sus lesiones intangibles, sino también una fuente para abonar los honorarios de su abogado ${ }^{55}$. Se ha convertido en una tradición norteamericana la idea de considerar la porción de la indemnización por daños morales, en lugar de una indemnización por pérdidas no económicas probadas, como la fuente primaria de retribución del abogado. Es decir, la parte de la indemnización que corresponde a las lesiones intangibles - en lugar de la indemnización total de la víctimasoporta la carga de la infracompensación inevitable producida por la regla americana ${ }^{56}$.

Algunos comentaristas han alegado que los jurados, cuando llevan a cabo la valoración del quantum indemnizatorio, tienen en cuenta que la víctima destinará parte de la indemnización para abonar los honorarios del abogado ${ }^{57}$. Sin embargo, un artículo del profesor Kalven (en el que hace un resumen de las conclusiones del Jury Project de la University of Chicago Law School) sugiere la opinión contraria ${ }^{58}$. De todas formas, el profesor Kalven reconoce que los jurados, frecuentemente son conscientes de los acuerdos de cuota litis, y debido a que este órgano llega a la indemnización global por un proceso no científico que refleja una mezcla de objetivos compensatorios y retributivos, la indemnización global podría incluir alguna dotación para honorarios que no puede ser detectada ${ }^{59}$.

A pesar de las dificultades conceptuales y de las incertidumbres sobre la valoración de la indemnización por el jurado se debe admitir que el papel que cumplen los daños no económicos en el abono de los honorarios de abogado es ampliamente reconocido tanto por la doctrina como por la jurisprudencia norteamericana. La medida de limitar la in-

55 Esta práctica la recogen, entre otros:

Hicks, G.A., «Statutory Damage Caps are an incomplete reform: A proposal for attorney fee shifting in tort actions», en Louisiana Law Review, vol. 49, 1989, pp. 763-801; Fleming, The American Tort Process... cit., p. 224; DobBs, D.B., Remedies: DamagesEquity-Restitution, Hornbook Series, St. Paul Minn., West Publishing Co., 1973, p. 550; MORRIS, «Liability for Pain \& Suffering», en Columbia Law Review, vol. 59, 1959, p. 476; O'Connell, J., «A Proposal to Abolish Defendant's Payment for Pain and Suffering in return for Payment of Claimants' Attorney's Fees», en University of Illinois Law Review, 1981, pp. 333-369.

56 Esta asunción parcialmente reconoce que las indemnizaciones morales carecen de legitimidad y que los jurados pueden fácilmente manipularlas para compensar pérdidas más demostrables.

57 Ver IngBeR, «Rethinking Intangible Injuries: A Focus on Remedy», en California Law Review, vol. 73, 1985, pp. 810-811; y MORRIS, op. cit., en p. 477.

58 Es de esta opinión, KALVEN, H., «The Jury, the Law, and the Personal Injury Damage Award», en Ohio State Law Journal, vol. 19, 1958, pp. 176-77.

59 Kalven, H., «The Jury, the Law, and the Personal Injury...», cit., pp. 176-77. 
demnización por pain and suffering fue una de las más importantes durante todo el movimiento de reforma. Pero, esta decisión tiene efectos secundarios evidentes: poner un límite en la indemnización por pain and suffering supone no sólo una disminución de la indemnización por lesiones extrapatrimoniales, sino también un ataque a las pérdidas económicas sufridas por la víctima. Por ejemplo ${ }^{60}$, si una persona gravemente lesionada ha probado unos daños económicos por un valor de 1.500 .000 dólares y daños no económicos por valor de 500.000 dólares, el efecto de un techo de 250.000 sobre la indemnización de daños no económicos disminuiría la indemnización de 2.000 .000 a 1.750.000. Si la víctima y su abogado acordaron un contingent fee de un $30 \%$, la indemnización de la víctima después de pagar los honorarios se reduciría de 1.400 .000 a 1.225.000. Esta reducción tendrá como consecuencia que la indemnización neta de la víctima sea inferior a sus daños económicos probados (1.500.000 dólares).

Es cierto que los casos que se verán afectados por este límite son una minoría, pero son los casos que tratan las lesiones más graves ${ }^{61}$. Sin embargo, el efecto de los límites en el quantum indemnizatorio del pain and suffering no sólo afectará a la cantidad recibida por la víctima, sino que, además, menoscaba su posibilidad de encontrar abogado y por lo tanto de recibir indemnización. Reduciendo la indemnización total, las leyes estatales que imponen techos sobre la indemnización de los daños morales reducen la probabilidad de que la indemnización sea adecuada para cubrir los gastos del proceso $^{62}$.

La doctrina norteamericana ha planteado diversas propuestas para evitar los efectos secundarios negativos, provocados por la combinación de las reformas adoptadas en las últimas décadas y la aplicación de la american rule y los contingent fees que tienen sobre las víctimas de los tort $^{63}$. Por ejemplo, el profesor O'Connell sugirió que se limita-

60 Ejemplo extraído del artículo del Profesor Hicks, «Statutory Damage Caps are an incomplete Reform...», cit., pp. 773-774.

61 La American BAR AsSOCIATIOn, Report of the Action Commission to Improve the Tort Liability System, ABA, 1987, p. 13, propuso que los límites legales sobre las indemnizaciones morales debían ser abandonados. Su argumento era que los límites tienen efectos devastadores en los lesionados más gravemente. La comisión recomienda que el sistema siga como estaba.

62 Ver MORRIS, «Liability for Pain and Suffering...», cit., p. 477; INGBER, «Rethinking Intangible Injuries...», cit., pp. 810-11; PECK, «Compensation for Pain: A Reappraisal in Light of New Medical Evidence», en Michigan Law Review, vol. 72, 1974, pp. 1.355 y ss.

${ }_{63}$ Entre las propuestas destacan las del profesor: O'Connell, op. cit.; la del profesor Hicks, en «Statutory Damage Caps are an incomplete Reform...», cit. y la del AMERICAN LAW InstituTE, Study on Enterprise Responsibility for Personal Injury... cit. 
sen las indemnizaciones de daños no económicos a unas cantidades nominales y que se indemnizasen a los demandantes victoriosos los honorarios de abogados junto con la compensación de «special damages» ${ }^{64}$. Una consecuencia de abolir o limitar los pagos de pain and suffering es la de proveer una fuente alternativa para el abono de los honorarios del abogado y otros costes de entablar la demanda. Esta propuesta no sugiere que el demandante pague los honorarios del demandado en el caso de que pierda.

64 O'ConNell parte de la asunción de que el abogado normalmente demanda una cantidad que es tres veces la suma de todas sus facturas para lograr la compensación de su cliente de pain and suffering y el pago de sus facturas. La tentación de hacer dinero fácil, junto con la frágil línea entre los gastos apropiados y exagerados por cuidados médicos incentiva a mucha gente - incluyendo a doctores, abogados, y víctimas de accidentes - a explotar el sistema. La asociación de TRIAL LAWYERS OF AMERICA ofrece guías al cliente para maximizar su indemnización por pain and suffering, ver DUDKIK, R. \& LEONARD, J., Instructions to clients in Anatomy of a personal Injury Law Suit: A Handbook of Basic trial advocacy, en Association of Trial Lawyers of America, 1968, pp. 20-21:

\section{INSTRUCTIONS TO CLIENTS «MY DAY»}

1. «MY DAY»- We have talked to you about «MY DAY» when you were in the office. We would like to start keeping a diary at once. This record will be very valuable throughout your case. It will be kept strictly confidential.

2. HOW THESE INJURIES HAVE AFFECTED YOUR LIFE- We call it «My Day» because we want to take a normal day, from the time you get up until the time you do to bed, and explain in detail how this occurence has changed your life. For example, the way you put on your clothes, the way you get in and out of bed, the way you take a bath, etc. By your life, we mean your work, your playtime, your hobbies, your life as a husband or as a wife, etc. This includes your disposition, your personality, your nervousness, etc. We need to know how your injury has affected the marital relations between you and your spouse.

3. YOUR PAIN AND SUFFERING- We want a description of your pain, both at the scene of the occurrence and at all times therafter. We want to know whether or how it is a shooting pain, throbbing pain, etc. We want your words and not anyone else's.

4. START AT YOUR HEAD WHEN RECORDING YOUR COMPLAINTS AND INJURIES- A good rule to follow in order to remember all of your problems is to start at your head and, in detail, go down through all parts of your body, moving from your head, neck, shoulders, etc. Explain in detail any problem that you have with each part of the body. Also, give details with regard to the medications you are taking and what they are for, if you know.

5. DON'T USE THE WORDS «I CAN'T»- Please do not use the words «I can't» because «can't» means physical impossibility. For example, you can't use your left hand, if you haven't got one. Don't say «I can't do it»; «I don't do it», «I never do it». We would prefer you would use such words as «I am not able to do it as well» or some other words meaning the same thin. You should always work toward the idea that «I'm trying and I will continue to try to do more things». Everyone will admire you more if you try. In regard to yours activities such as your housework, your yardwork, your work at the office or factory, you should detail what things you are not able to do as well as before. 
Una propuesta interesante ha sido la del American Law Institute65, que ha apuntado las siguientes medidas:

1) Los honorarios razonables de los abogados y otros gastos incurridos por el demandante vencedor deben ser tratados como categoría de la indemnización compensatoria, en línea con el papel principal del Derecho de daños de reembolsar a las víctimas sus pérdidas pecuniarias que no están cubiertas por otras formas de seguro.

2) Debe crearse un procedimiento de oferta de negociación («offerof-settlement») bajo el cual una vez que el demandado hace una oferta de negociación formal, si se rechaza por el demandante y éste no recibe una cantidad mayor (o por lo menos igual) en la indemnización eventual, entonces se verá privado de su derecho a indemnización por los honorarios incurridos - después de un período razonable para considerar la oferta-.

3) Los tribunales utilizarán una fórmula basada en porcentajes sobre la indemnización como forma de calcular la indemnización de honorarios de la víctima.

\section{ANALISIS DE LA SITUACION EN EUROPA}

Con la excepción de Gran Bretaña y los países Escandinavos, los países europeos cimientan los principios que gobiernan el procedimiento civil en el Derecho romano.

Durante el período clásico del Derecho romano, la Administración de Justicia mantenía la dignidad y el aura sacra de sus orígenes religiosos ${ }^{66}$,

6. «MY DAY» WITNESS- We would like for you to contact your friends, neighbords, associates at work, etc., and on a separate sheet of paper of each witness give us his name, address and telephone number. Have each describe, or you describe in detail, on a separate sheet of paper what he or she knows about how this injury has changed your life... It is better if these witnesses are not your relatives. It is alright if they are your friends, because they would be more likely to have observed you. It is impossible to be too detailed.

9. USE YOUR IMAGINATION- You know your own life better than we do. Use your imagination and go into all aspects of your life. Explain to us, in the greatest detail possible, how this occurence has affected your life.

65 AMERICAN LAw InSTITUTE, The American Law Institute's Reporters' Study on Enterprise Responsibility for Personal Injury..., vol. II, cit., pp. 315-316.

${ }^{66}$ En la legis actio sacramentum, cada parte tenía que hacer un depósito (un sacramentum) dentro del templo; cuando se alcanzaba una decisión, a la parte ganadora se le devolvía su depósito, mientras que el del perdedor quedaba para el templo (EngELmann, The Roman Procedure en A History of Continental Civil procedure, pp. 239-271 (R. Miller ed. \& trans. 1927)). Este tipo de procedimiento se utilizaba antes de la compilación de las 12 tablas (sobre el 450 a.C.); las 12 tablas fijaron las cantidades de depósito (Ver M. voN Bethmann-Hollweg, Der Römische Civil prozess, Erster Band: Legis Actiones 121(1864)). 
y el procedimiento legal y el asesoramiento eran gratuitos ${ }^{67}$. En los tiempos de Justiniano, como consecuencia del alto desarrollo administrativo del Imperio Bizantino, los abogados comenzaron a percibir honorarios ${ }^{68}$. Cuando los costes legales se convirtieron en una realidad del proceso, con una regulación más detallada que determinaba la incidencia y cantidades, se extendió la práctica de requerir que la parte perdedora reembolsara al ganador sus costes en los casos de demandas frívolas y para los casos en los que se pruebe la existencia de mala fe. El emperador romano Zenón fue el que anunció por primera vez, en el 486 d.C., la regla de que el mero hecho de perder era base suficiente para imponer en el perdedor la obligación de pagar los costes legales del ganador. Cincuenta años después la regla pasó a formar parte del Código de Justiniano ${ }^{69}$. La presunción dominante era que la parte perdedora había actuado mal en insistir en su posición legal, ya que como la decisión del tribunal demostró, no estaba justificada. Sin embargo, el juez tenía poder para no aplicar la regla general cuando existían dudas suficientes sobre la mala fe de la parte perdedora.

Posteriormente, la regla fue adoptada por los tribunales eclesiásticos de la Iglesia Católica Romana, y eventualmente por los tribunales de las naciones europeas emergentes ${ }^{70}$.

En Inglaterra, la conexión con el Derecho romano es menos obvia, aunque no puede ser ignorada ${ }^{71}$. Las normas inglesas sobre costes legales evolucionaron de manos de una legislación parcial y con el ejercicio del poder discrecional del Chancellor.

\section{Reglas europeas}

No existe una regla que se pueda denominar la «regla europea». Las normas de los países europeos sobre los costes legales no son uniformes. Sin embargo, a excepción de Inglaterra (en donde el tribunal tiene poder discrecional sobre si conceder los costes o no) un gran número de códigos europeos prescriben que los tribunales deben imponer

67 Ver Wenger, L., Institute of the Roman Law of Civil Procedure, pp. 330-331 (rev. ed. 1940).

68 Para el tiempo de Dioclatiano (300 d.C.) se consideró necesario regularlos.

69 Código de Justiniano, 7.51.5.

70 Endemann, W., Das Deutsche Zivilprozessrecht, p. 507 (1868 \& reprint 1969), citado en Pfennigstorf, W., «The European Experience...», cit., p. 42.

71 Ver F. Pollock \& F. Maitland, The History of English Law, 2a de., University Press, Cambridge, 1952, p. 134. 
los costes legales en la parte perdedora ${ }^{72}$. La regla se aplica tanto si la parte perdedora es el demandante como si es el demandado, aunque raramente se define esta situación en los códigos ${ }^{73}$.

Las razones que se han esgrimido en apoyo de este sistema de costes han variado con el paso del tiempo ${ }^{74}$. En un primer momento se alegó el castigo y la disuasión de ciertos comportamientos que suponían un abuso del sistema judicial por acciones no fundadas, vejatorias, o frívolas $^{75}$. La razón más extendida en Europa es la de compensación total de la parte ganadora ${ }^{76}$. La idea que subyace bajo este principio - algunas veces conocido como el principio de «net-of-cost» o «valor total»- expresa que el litigante que se ve obligado a interponer una acción en los tribunales (o a defenderse) tiene derecho a recobrar el valor total de su demanda y no debería considerarse satisfecho con una cantidad menor debido a la necesidad de interponer una demanda (o una contestación). Este argumento ha sido utilizado en Italia ${ }^{77}$, en Francia $^{78}$ y recientemente en Alemania ${ }^{79}$.

72 Ver, por ejemplo la sección 41 del Código de Procedimiento civil de agosto de 1895 , Austria, sección 41:

«1) La parte que pierda totalmente en el proceso debe reembolsar al oponente, así como la parte que intervenga en el lugar del anterior, todos los costes que se le hayan causado al litigante y que fueran apropiados. Los costes que se consideren necesarios deben de ser determinados por el tribunal cuando se especifique su cantidad, sin permitir la presentación de pruebas, en base a su discreción guiada por consideraciones cuidadosas de todas las circunstancias.

2) Si los honorarios del abogado o el quantum de los costes está regulado en tablas, la valoración de la cantidad de costes debe estar basada en las tablas.»

Ver, también: Bélgica art. 1.017, Dinamarca, sección 321(1), Francia art. 696, Ginebra art. 122(1), Alemania sección 91(1), Italia art. 91, Holanda art. 56, Noruega sección 172 , Suecia cap. 18, 1 .

${ }^{73}$ La mayoría de los códigos se refieren a la parte ganadora o perdedora, sin determinar si es demandante o demandado.

${ }^{74}$ Por ejemplo, promover la justicia, hacer que la víctima sea compensada totalmente por el mal sufrido, castigar al demandado por su acto ilícito, incentivar los procesos que se consideran útiles para la sociedad, rectificar las grandes disparidades entre las partes, crear incentivos económicos para ciertos comportamientos deseables en el proceso.

75 Endemann, W., «Das Deutsche...», cit., pp. 505-506.

76 El Código de Procedimiento de Finlandia en el capítulo 21, sección 1, recoge que la parte que pierde el caso tiene la obligación de reembolsar los gastos legales a su oponente, a no ser que se estipule otra cosa. La ley se basa en la asunción inicial de compensación total de los costes.

77 Vecchione, Spese Giudiziali (Diritto processuale civile) en 17 Novissimo Digesto Italiano en 1124-25.

${ }^{78}$ L'Association Nationale Des Avocats, Au Service de la Justice: La Profession Juridique de Demain., cit., en Pfennigstorf, W., «The European Experience...», cit., p. 47.

79 GRUNSKY, Empfehlen sich im Interesse ainer effektiven Rechtsverwirklichung für alle Bürger Änderungen des Systems des Kosten- und Gebührenrechts?, en Verhandlungen Des Einundfünfzigsten Deutschen Juristentages, A67, 1976. 
También se ha alegado que la obligación de soportar los costes del proceso es necesaria para permitir un acceso no restringido a los tribunales. Para otros autores, como por ejemplo Endemann, la imposición de costes a la parte perdedora se ha considerado como algo «natural» ${ }^{80}$; es decir, que durante los siglos se ha convertido en parte de la percepción popular del Derecho y de los procedimientos legales por lo que no necesita justificación. Los largos períodos de prácticas y aceptación proveen de justificación suficiente.

«Derrotar, Vencer, Ganar» se entiende como pérdida completa de los aspectos principales del caso. Por lo tanto no es una excepción a la regla, sino una matización, cuando un código establece que si una parte prevalece en algunos aspectos, pero pierde en otros, los costes deben dividirse proporcionalmente entre ambos ${ }^{81}$.

Uno de los casos más importantes de victoria parcial es cuando la sentencia concede al demandante una cantidad menor de la pedida en la demanda. Se reconoce generalmente que con relación a la diferencia entre la cantidad pedida y la cantidad concedida, el demandante ha perdido y debe soportar una parte proporcional de los costes totales ${ }^{82}$. En Noruega, el Tribunal Supremo en $1985^{83}$ en un caso en el que el demandante solicitaba 100.000 coronas noruegas como compensación por los daños sufridos y sólo se le indemnizó con 10.000 coronas noruegas, el tribunal consideró que esta situación representaba una pérdida total para el demandado y le condenó a cubrir sus costes legales.

Las reglas inglesas sobre costes legales tienen ciertas peculiaridades frente a la gran mayoría de los países estudiados. Normalmente, el demandante tiene derecho a que se le abonen todos sus costes legales, aun en el caso de que el tribunal le conceda una cantidad menor a la cantidad demandada, excepto cuando exista una mala conducta relacionada con la prosecución de una demanda excesiva ${ }^{84}$. En Inglaterra, el

80 Endemann, W., «Das Deutsche...», cit., p. 506. Ver Pfennigstorf, W., «The European Experience...», cit., p. 43.

81 Por ejemplo la sección 43 del Código de Procedimiento civil en Austria, el artículo 92 del Código italiano y el art. 65(1) de la Ley holandesa.

82 Ver, por ejemplo: art. 43(1) Código de Procedimiento civil de Austria, art. 179 del Código de Procedimiento civil de Grecia.

Algunos códigos establecen que los costes no necesitan ser divididos si la diferencia es menor y no causa costes adicionales. Ver, por ejemplo: El Código de Procedimiento civil austriaco, artículo 43(2); la sección 316(2) del Código de Dinamarca; la sección 174 del Código de Noruega.

83 RT 1985/505.

84 Ver, por ejemplo, Pearman v. Baroness Burdett-Coutts, 3 T.L.R. 719, 720 (1887) (al demandante se le negó la indemnización de los costes legales después de haber demandado 600 libras como indemnización y haber recibido por el tribunal sólo 50 libras). 
demandado puede trasladar el riesgo del coste legal parcialmente al demandante mediante «el pago en el tribunal» («paying into court») de una cantidad que constituye su oferta de negociación, la cual el demandante puede aceptar o no. Si el demandante acepta, el caso se termina y tiene derecho a sus costes legales. Si se mantiene en la petición de una indemnización mayor y tiene éxito, también tiene derecho a sus costes legales por la cantidad total. Pero si la sentencia no es igual o es menor que la cantidad indemnizada por el tribunal, el demandante, aunque haya tenido éxito, debe reembolsar al demandado los costes en los que éste haya incurrido después del momento en que hizo el "paying into court». El espíritu de esta norma es claramente el de incentivar las negociaciones entre las partes.

Aunque se reconoce que el hecho objetivo de perder es base suficiente para imponer los costes en la parte perdedora, también se reconocen ciertas excepciones y matizaciones a la regla general.

Las siguientes son algunas de las excepciones más comunes:

1. Acción no provocada: Si un demandado no ha provocado al demandante y reconoce la demanda inmediatamente, demostrando con ello que la acción no era necesaria, usualmente no sólo se verá libre de la obligación de pagar los costes del demandante ${ }^{85}$, sino que el demandante - aunque técnicamente sea el ganador - será obligado a pagar los costes legales del demandado ${ }^{86}$.

2. Ignorancia excusable de hechos materiales: Si el demandante gana en base a unos hechos que el demandado no conocía o no podía esperarse que conociera antes del comienzo de la acción, el Código sueco permite que los costes se repartan entre las partes ${ }^{87}$.

3. Dudas substanciales mutuas sobre los hechos: Estas dudas pueden justificar que la parte litigue de buena fe, así como justificar la decisión de repartir los costes entre las partes ${ }^{88}$.

4. Dudas sobre la ley: Los tribunales y parlamentos han sido reticentes a reconocer el valor de las dudas que sobre la ley tengan las partes del proceso. Sólo las reconoce el Código noruego ${ }^{89}$. En otros países,

85 Por ejemplo, el Código de Suecia, capítulo 18, 3.

86 Ver, por ejemplo, el Código de Procemiento civil de Austria, sección 45.

87 Ver el capítulo 18, 3 del Código de Suecia.

${ }^{88}$ El Código de Procedimiento civil de Grecia en el artículo 179 permite que no se indemnicen los costes legales si el tribunal llega a la conclusión de que el perdedor «tuvo dudas justificadas sobre el resultado del caso».

89 Ver la sección 172 del Código de Noruega. 
la doctrina ha declarado que las dudas sobre la ley aplicable no suponen una excepción a la regla general ${ }^{90}$.

5. Apelaciones: Parece justo que si se niega la apelación la parte perdedora corra con los gastos. Pero, si la apelación tiene éxito y la sentencia del tribunal menor es negada, la parte que ganó en el nivel menor y sólo ha perdido en apelación puede argumentar que al menos un tribunal estaba de acuerdo con su postura, por lo que no estaba del todo equivocado al interponer o contestar a la demanda. El argumento es más persuasivo cuando el caso, como consecuencia de la apelación, da lugar a un nuevo juicio. La regla general es que todos los costes legales incurridos en todos los niveles siguen al resultado final del caso $^{91}$.

Existe una excepción importante: si la decisión apelada se basa en hechos nuevos que podían haber sido presentados en el tribunal menor (y presumiblemente habrían hecho la apelación innecesaria) los costes de la apelación pueden recaer sobre la parte ganadora ${ }^{92}$.

6. Procedimientos innecesarios: La parte ganadora tiene derecho a reembolso sólo por aquellos costes que fueran necesarios para ganar la acción ${ }^{93}$. Esto supone una limitación de los tipos y de las cantidades de gastos reembolsables. Limitar la aplicación de la regla a los costes legales necesarios ha hecho que estas reglas se conviertan en una herramienta para promover la economía procesal, la obligación de buena fe, la apertura y la cooperación entre los litigantes.

Consecuentemente, si la parte ha causado costes por procedimientos innecesarios, no sólo verá impedido el reembolso de sus propios costes, sino que deberá reembolsar los de la otra parte, sin tener en cuenta el resultado.

7. Acciones entre parientes: Los Códigos de Bélgica y Holanda contienen regulaciones expresas sobre esta cuestión ${ }^{94}$. La razón parece estar en los especiales lazos económicos y sociales que existen entre los parientes.

Respecto al procedimiento utilizado por los tribunales para calcular los costes legales, dos son las prácticas más extendidas. En algunas ju-

\footnotetext{
90 Ver Pfennigstorf, W., «The European Experience...», cit., p. 50.

91 Ver, por ejemplo:

La sección 50 del Código de Austria; la sección 318 del Código de Dinamarca; el capítulo 18, 15 del Código de Suecia.

92 Ver la sección 97 (2) del Código de Alemania.

93 Ver la sección 41(1) del Código de Austria; la sección 312(2) del Código de Dinamarca; la sección 91(1) del Código de Alemania.

94 Ver el artículo 1.017 del Código de Bélgica y el artículo 56(1) del Código de Holanda.
} 
risdicciones, el tribunal, en la sentencia, decide qué parte tiene que soportar los costes totales o qué fracción de los costes totales debe nacer en una u otra parte. En estos casos, la cantidad precisa por costes legales se concreta posteriormente por los oficiales del tribunal. Así se hace en Inglaterra, Alemania e Italia. En un segundo grupo de jurisdicciones, es el tribunal el que decide la cantidad económica concreta de costes legales que debe ser indemnizada ${ }^{95}$. El código francés diferencia entre los costes del tribunal que son valorados en la sentencia ${ }^{96}$ y otros gastos incurridos por la parte ganadora que son determinados por los oficiales del tribunal ${ }^{97}$.

En España, el movimiento a favor de establecer la regla del vencimiento en el tema de las costes legales se plasmó en la Ley de Reforma Urgente de la ley de Enjuiciamiento Civil del 6 de agosto de 1984. Esta Ley incorporó una nueva sección en el capítulo dedicado a las Disposiciones Generales de los juicios declarativos compuesta de un solo artículo, el 523, bajo la rúbrica «De la Condena en Costas». Antes de la Ley del 6 de agosto de 1984, la Ley de Enjuiciamiento Civil carecía de una regulación general sobre el pago de costas. Sólo en algunos juicios o instancias se imponían las costas al litigante vencido ${ }^{98}$. El Tribunal Supremo había resuelto esta laguna legal con la regla general de que cada parte debía satisfacer sus costas y las comunes por mitad. La excepción a la regla general consistía en que se imponían las costas sobre el litigante en que se apreciara temeridad o mala fe en su actuación procesal, bien al demandar o al oponerse ${ }^{99}$.

A partir de 1984, la regla general es que se imponen las costas de primera instancia a la parte cuyas pretensiones hubieran sido totalmente rechazadas ${ }^{100}$. Excepcionalmente, la Ley permite que el Juez, aun desestimando totalmente las pretensiones de una parte, no imponga las costas por concurrir «circunstancias excepcionales». La Ley no señala cuáles pueden ser esas «circunstancias excepcionales», lo cual deja un amplio margen a la discrecionalidad judicial.

Para los casos en los que se estima o desestima de forma parcial las pretensiones de las partes, la Ley señala un criterio general y otro ex-

\footnotetext{
95 Por ejemplo la sección 53 del Código de Austria; la sección 312(2) del Código de Dinamarca; el artículo 56(3) del Código de Holanda.

96 Ver el artículo 710 del Código de Francia.

97 Ver los artículos 704-708 del Código de Francia.

98 Por ejemplo el art. 1.582 de la Ley de Enjuiciamiento Civil.

99 EI fundamento para esta excepción estaba en la responsabilidad extracontractual recogida en el art. 1.902 del Código civil.

${ }^{100}$ El criterio objetivo de vencimiento rige también para las costas causadas en la segunda instancia o alzada.
} 
cepcional. El criterio general es que en estos casos cada una de las partes debe pagar las costas causadas a su instancia y las comunes por mitad. El criterio excepcional es que, no obstante, aun con estimación parcial de las pretensiones de las partes, se pueden imponer las costas a una sola que hubiese litigado con temeridad.

\section{Situación en Europa de los contingent fees}

Existe un punto de acuerdo general entre los países europeos sobre los acuerdos de cuota litis - del tipo comúnmente utilizado en los Estados Unidos en los casos de responsabilidad por lesiones personalessegún el cual están, o bien prohibidos expresamente, o bien no se consideran éticos.

La práctica jurídica norteamericana parece aceptar los honorarios contingentes como una alternativa preferible a la ayuda legal. Los europeos, en contraste, parecen considerar la ayuda legal como respuesta preferible y están menos inclinados a abandonar posturas éticas tradicionales en relación a los acuerdos contingentes ${ }^{101}$.

La aceptación de los contingent fees en los Estados Unidos no plantea serios problemas porque, bajo la regla americana, el litigante sólo tiene que preocuparse por sus propios costes, y los acuerdos contingentes ofrecen una respuesta, gane o pierda. Un demandante europeo, en contraste, si pierde el caso debe abonar los honorarios de la otra parte, y para esta posibilidad, el acuerdo cuota litis no parece una respuesta adecuada. En opinión del profesor Pfennigstorf ${ }^{102}$, se podría decir que los europeos, en contraste con los norteamericanos, desarrollaron el seguro de gastos legales con anterioridad. Este seguro resuelve los problemas del demandante europeo mejor que el contingent fee, puesto que no sólo cubre los honorarios de su propio abogado — sin reducir la cantidad de la indemnización recibida por el demandante- sino que también los costes legales del oponente en el caso de que pierda ${ }^{103}$.

Finalmente, mientras que las jurisdicciones europeas son uniformes ${ }^{104}$ en cuanto a negar la práctica de los contingent fees, en al menos

101 Ver VIGORITI, «Access to Justice in Italy», en Access to Justice, vol. 2, 1979, pp. 649 y ss.

102 Pfennigstorf, W., «The European Experience...», cit., p. 61.

${ }^{103}$ Pfennigstorf, W., «The European experience in Legal Expense Insurance», en Legal Services Plans: Approaches to Regulation, 1977, pp. 487 y ss.

104 Por ejemplo, en Austria los pactos de cuota litis están prohibidos en el art. 879 del Código civil general. También en Bélgica (art. 459 del Código Judicial), Holanda (Code of Conduct od Advocates 1992, rule 25). 
algunas de ellas las reglas existentes sobre la forma de calcular los honorarios de los abogados producen resultados que en muchos aspectos son similares a los acuerdos de contingent fee, especialmente si se contempla a los litigantes de baja renta.

El criterio más importante para establecer los honorarios de los abogados en muchos países europeos es la cantidad en controversia. La cantidad de trabajo realmente realizado es raramente considerada. Así, el honorario de un abogado que representa una demanda de lesiones personales es mayor si la cantidad indemnizatoria reclamada y concedida es notable. Si la indemnización es pequeña, los honorarios del abogado también serán pequeños, sin tener en cuenta el número de horas invertidas en el caso.

El resultado es, en opinión de Pfennigstorf ${ }^{105}$, y desde la perspectiva del abogado, no muy diferente al de la regla americana de honorarios contingentes. Desde la perspectiva del cliente, existe una diferencia importante. Si el tribunal decide a su favor, recibe el $100 \%$ de la cantidad indemnizatoria dada por el tribunal, y los honorarios de su abogado serán abonados por su oponente. Si el tribunal rechaza la demanda, se enfrenta a las obligaciones legales tanto de su abogado como a las del abogado del demandado.

\section{Algunos supuestos concretos (en particular, procesos civiles de reclamación de daños a la persona) ${ }^{106}$}

En Australia los acuerdos de cuota litis están prohibidos. Sin embargo, existen algunas firmas de abogados que aceptan casos de lesiones a la persona en base a «si no se gana no se cobra».

En Austria el derecho del abogado a recibir remuneración se recoge en la Attorney's Fee Ordinance y depende no sólo del tipo de trabajo realizado sino también de la cantidad en disputa. No se permiten los acuerdos de contingent fees, la prohibición se recoge en el Código civil general, artículo 879.

En Alemania los acuerdos de contingent fees están prohibidos. El principio general es que los costes legales (incluidos los honorarios del abogado) forman parte de la demanda. Todos los casos por lesiones personales siguen un catálogo de honorarios establecido por ley, aunque se permite la posibilidad de un acuerdo separado entre el abogado

105 Pfennigstorf, W., «The European Experience...», cit., p. 61.

106 Para más información ver, International Personal Injury Compensation, General Editor: CAMPBELL, D., Swett \& Maxwell, London,1996. 
y su cliente. Si hay acuerdo entre el abogado y el cliente, por ejemplo que los honorarios del primero serán de 10.000 marcos, pero el catálogo legal establece un pago de 4.000 marcos, si asumimos que ganan el caso, la parte perdedora esta obligada a pagar sólo la cantidad que establece el catálogo. Si pierden el caso, el cliente está obligado a pagar los 10.000 marcos acordados, así como los costes de la otra parte establecidos según el catálogo

En Bélgica también se prohíben los acuerdos contingentes (Código Judicial, art. 459). Para el cálculo de los honorarios se utilizan los criterios de: situación final del cliente, la importancia y urgencia de la cuestión, la dificultad del caso y el resultado y, por último, la experiencia y conocimientos del abogado.

En Dinamarca, la Det Danske Advokatsamfund ha establecido ratios fijos para el cálculo de los honorarios. El honorario es un porcentaje del valor del caso, pero puede ser alterado dependiendo de la naturaleza del caso y de factores como la complejidad e importancia del mismo y el tiempo dedicado. En Dinamarca se permite el acuerdo entre el abogado y el cliente para que los honorarios del abogado sean mayores si el caso se gana. Sin embargo, está prohibido el acuerdo por el que el honorario constituiría una parte concreta de la indemnización de la víctima.

En Francia, no hay una regla general que gobierne los honorarios de los abogados. Algunos abogados basan sus honorarios en un ratio horario, otros acuerdan con sus abogados una cantidad fija más un plus basado en los resultados alcanzados. La parte del honorario basada en los resultados alcanzados debe ser «razonable». Como regla general, los acuerdos de cuota litis están prohibidos. En los casos civiles, el abogado tiene derecho a moluments; es decir, a un tipo de remuneración establecida de acuerdo con una escala nacional. Parece que en la práctica los abogados, en los casos de lesiones personales normalmente basan sus honorarios en el resultado obtenido más que en la escala nacional, ya que las cantidades que resultan de esta última son pequeñas.

En Holanda los honorarios indemnizados por el tribunal tienen que estar basados en la Liquidatie-tarief Rechbanken en Hoven. El punto de partida de esta tarifa es que un cliente nunca resultará indemnizado con el $100 \%$ de sus costes legales. La tarifa no es muy generosa, y usualmente sólo el $10 \%$ o el $15 \%$ de los honorarios serán reembolsados a la parte ganadora. Los honorarios se establecen teniendo en cuenta las circunstancias de cada caso, y según el Código de conducta de los abogados de 1992, regla 25, no pueden ser muy altos pero tampoco muy bajos. En este código también se recoge la prohibición del pacto de cuota litis. Sin embargo, en Holanda sí encontramos una tarifa básica 
horaria que se revisa cada pocos años (el 1 de enero de 1996 la tarifa era de 290 NGL). En un futuro cercano, los honorarios quedarán al arbitrio de cada firma en particular.

En Nueva Zelanda, aunque los acuerdos contingentes no están prohibidos de forma expresa por la regla 3.01(4) de la Rules of Proffesional Conduct for Barristers and Solicitors, la decisión del Tribunal de Apelación inglés de Wallersteiner v. Noir ${ }^{107}$ y la de Tribunal de Apelación de Nueva Zelanda de Mills v. Rogers ${ }^{108}$ han hecho que para algunos supuestos los acuerdos de cuota litis se consideren contrarios al orden público. Como resultado, no es común que las firmas de abogados de Nueva Zelanda basen sus honorarios en acuerdos contingentes, sino más bien en las horas dedicadas y el tipo de caso.

En Noruega tampoco se permiten los acuerdos de cuota litis, llamados «no cure, no pay», y el honorario normalmente se establece en base al trabajo realizado por el abogado.

En la provincia de British Columbia de Canadá existen tres métodos convencionales para retribuir el trabajo del abogado: el acuerdo de un honorario fijo, un ratio horario, y los acuerdos de contingent fee. El método más común en los casos de lesiones a la persona es el del contingent fee. Los porcentajes varían, pero se suelen mover entre el $25 \%$ y el 33,33\%, dependiendo de la magnitud y de la complejidad de la demanda. El porcentaje raramente excede del $40 \%$. Para cuestiones distintas a las lesiones a la persona el método comúnmente utilizado es el del ratio horario.

En España, los honorarios de los abogados se fijan libremente, teniendo en cuenta diversos factores: cuantía económica del asunto, dificultad, éxito, etc. No existe ninguna regla general, aunque los Colegios de Abogados acostumbran a promulgar unas normas, bien de orientación, bien fijando unos honorarios mínimos, para evitar la competencia desleal. Las normas colegiales no tienen carácter vinculante.

El Real Decreto Ley 5/96, de 7 de junio, de medidas liberalizadoras en materia de suelo y de Colegios Profesionales (BOE n. ${ }^{\circ} 139$ ) modifica la Ley 2/1974, de 13 de febrero, reguladora de los Colegios Profesionales. Se modifica el art. 2.1. que queda redactado de la siguiente forma:

«El Estado y las Comunidades Autónomas, en el ámbito de sus respectivas competencias, garantizan el ejercicio de las profesiones colegiadas de conformidad con lo dispuesto en las Leyes.

107 (No. 2) (1975) Q.B. 373.

108 (1899) 18 N.Z.L.R. 291. 
El ejercicio de las profesiones colegiadas se realizará en régimen de libre competencia y, sin perjuicio de la legislación general y específica aplicable en la ordenación sustativa propia de cada profesión, estará sujeto, en cuanto a la oferta de servicios y fijación de su remuneración, a la Ley sobre Defensa de la Competencia y a la Ley sobre Competencia Desleal.»

Se introduce un nuevo apartado 4 en el artículo 2, con la siguiente redacción:

«Los acuerdos, decisiones y recomendaciones de los Colegios con trascendencia económica observarán los límites del artículo 1 de la Ley 16/1989, de 17 de julio, de Defensa de la Competencia, sin perjuicio de que los Colegios puedan solicitar la autorización singular prevista en el artículo 3 de dicha Ley.»

Se modifica el párrafo ñ) del artículo 5, que queda redactado de la siguiente forma:

«ñ) Establecer baremos de honorarios, que tendrán carácter meramente orientativo.»

Para evitar el posible abuso - por parte del vencedor o su letradoen el momento de fijar sus honorarios, se establece un límite en el caso de condena en costas: el condenado sólo estará obligado a pagar — de la parte que corresponde a los abogados, peritos y demás funcionarios que no estén sujetos a aranceles- una cantidad total que no exceda de la tercera parte de la cuantía del proceso; a estos efectos las pretensiones inestimables se valorarán en un millón de pesetas ${ }^{109}$.

\section{POSTURA DEL ANALISIS ECONOMICO DEL DERECHO}

Resulta muy difícil — si no imposible- contestar a la pregunta de si la diferencia entre las reglas europeas y norteamericanas suponen una diferencia real en el mundo de las demandas judiciales, en la congestión de los tribunales y los retrasos. En otras palabras, ¿tienen las reglas europeas sobre costes legales un mayor efecto disuasorio para los posibles litigantes o por el contrario incentivan estas reglas un mayor número de demandas?

La búsqueda de una respuesta para esta pregunta nos llevaría en primer lugar a analizar qué se considera por demanda «buena»o «mala», lo cual es casi imposible de contestar con criterios objetivos.

109 Este límite no rige cuando el Juez estime la temeridad del litigante condenado a costas, Ley de Enjuiciamiento civil, art. 523.4ㅇ. 
En los Estados Unidos existe una amplia literatura, dentro del campo del análisis económico del Derecho, que ha tratado de responder a estas cuestiones. El Juez Posner y el profesor Shavell llegaron a la conclusión de que la regla inglesa reduce la probabilidad de la negociación entre las partes ${ }^{110}$, es decir, que da lugar a un menor volumen de negociación extrajudicial.

Posner y Shavell comienzan con la asunción de que las partes en el proceso estimarán en términos económicos cuál será la tarifa si es que van a juicio ${ }^{111}$. Estos autores asumen que son tres los factores relevantes en la toma de esta decisión: la probabilidad de que el demandante tenga éxito en el proceso, la cantidad en controversia, y los costes legales de ambas partes. De acuerdo con esta premisa, pongamos que Pp representa la estimación del demandante de su probabilidad de tener éxito en el juicio, Pd la estimación que hace el demandado de que el demandante tendrá éxito en el juicio, D será la indemnización que se concederá por el tribunal si el demandante tiene éxito, y $\mathrm{Cp}$ y $\mathrm{Cd} \operatorname{los}$ costes legales en los que incurrirán el demandante y el demandado respectivamente.

La regla americana: El beneficio esperado para el demandante (BEp) y el coste esperado (CEd) para el demandando por ir a juicio serán:

(1) $\mathrm{BEp}=\mathrm{Pp} \times \mathrm{D}-\mathrm{Cp}$

(2) $\mathrm{CEd}=\mathrm{Pd} \times \mathrm{D}-\mathrm{Cd}$

Posner y Shavell asumen que el caso será negociado si BEp $<$ CEd, porque en este caso la cantidad resultante de la negociación colocará a las partes en mejor posición de la que esperan estar si van a juicio. Por lo tanto, la condición para que se dé la negociación es:

(3) $\mathrm{Pp} \times \mathrm{D}-\mathrm{Cp}<\mathrm{Pd} \times \mathrm{D}+\mathrm{Cd}$, o de forma equivalente

(4) $\mathrm{Pp}-\mathrm{Pd}<(\mathrm{Cp}+\mathrm{Cd})$ (división) $\mathrm{D}$.

La regla inglesa: El requisito de que la parte perdedora deba pagar los costes de ambas partes afectará a los costes y a los beneficios esperados de ir a juicio. Los costes legales esperados de cada parte deberán estimarse en base a la probabilidad de que pierda, y ser luego multipli-

110 Posner, Economic Analysis of Law, 3. a ed., Little Brown and Company, Boston, 1986, pp. 537-40; Shavell, Economic Analysis of Accident Law, Harvard University Press, Cambridge, Mass, 1987, p. 65.

111 Ver Posner, Economic Analysis of Law... cit, p. 523; SHAVell, Economic Analysis of Accident Law... cit., p. 56. 
cados por la suma de $\mathrm{Cp}$ y $\mathrm{Cd}$. Teniendo en cuenta este hecho, podemos computar los beneficios esperados para el demandante y los costes esperados para el demandado de ir a juicio:

(5) $\mathrm{BEp}=\mathrm{Pp} \times \mathrm{D}-((\mathrm{I})-\mathrm{Pp})(\mathrm{Cp}+\mathrm{Cd})$

(6) $\mathrm{CEd}=\mathrm{Pd} \times \mathrm{D}+\mathrm{Pd}(\mathrm{Cp}+\mathrm{Cd})$

Nuevamente, la condición para que se dé la negociación es que BEp $<$ CEd, o

(7) $\mathrm{Pp} \times \mathrm{D}-((\mathrm{I})-\mathrm{Pp})(\mathrm{Cp}+\mathrm{Cd})<\mathrm{Pd} \times+\mathrm{Pd}(\mathrm{Cp}+\mathrm{Cd})$

lo que da lugar a la siguiente condición:

(8) $\mathrm{Pp}-\mathrm{Pd}<((\mathrm{I})-\mathrm{Pp}+\mathrm{Pd})(\mathrm{Cp}+\mathrm{Cd})$ (división) $\mathrm{D}$.

La primera cuestión a resaltar sobre las diferencias en (4) y (8) es que si $\mathrm{Pp}=\mathrm{Pd}$, las dos condiciones son equivalentes. En otras palabras, el resultado bajo la regla americana o bajo la regla inglesa será idéntico cuando las partes tengan la misma visión sobre la probabilidad de éxito en el tribunal. Segundo, debido a que las fórmulas del (4) y del (8) difieren en su parte derecha, parece claro que cuando $\mathrm{Pp}$ y $\mathrm{Pd}$ no sean iguales, las condiciones de negociación son diferentes bajo la regla americana y bajo la regla inglesa. Sin embargo, con este análisis todavía no está claro si el paso del sistema americano al sistema británico incrementará o descenderá el nivel de negociaciones entre las partes.

Supongamos que los costes totales son aproximadamente la mitad de la indemnización total en caso de que se llegue a un proceso. En otras palabras $(\mathrm{Cp}+\mathrm{Cd}): \mathrm{D}=0,5$. Colocando esta suposición en (4) y (8) nos da las siguientes condiciones de negociación:

\section{Regla americana}

(9) $\mathrm{Pp}-\mathrm{Pd}<0,5$.

Regla inglesa

(10) $\mathrm{Pp}-\mathrm{Pd}<((\mathrm{I})-\mathrm{Pp}+\mathrm{Pd}) \times 0,5$, lo cual es equivalente a:

(11) $\mathrm{pp}-\mathrm{P}<0,33$.

Bajo ambos regímenes legales, cuando el demandante sea menos optimista que el demandado sobre sus posibilidades de éxito - es decir si $\mathrm{Pp}<\mathrm{Pd}$ - el caso se negociará porque las condiciones (9) y (11) se ven satisfechas. Pero en los casos en los que Pp > Pd, casos en los que las partes son ambas relativamente optimistas, la sección (9) indica que, bajo el sistema americano, la diferencia entre las estimaciones del demandante y del demandado sobre la posibilidad de éxito en el proce- 
so tiene que exceder del 0,5 para que el caso vaya a juicio. La sección (11) revela que, bajo la regla inglesa, el nivel de desacuerdo dentro del cual la negociación tendrá lugar es sólo de 0,33. En otras palabras, lo que Posner y Shavell están diciendo es que el nivel de negociaciones en los Estados Unidos descenderá si se adopta la regla inglesa sobre costes legales. De acuerdo con estos autores, la oportunidad de evitar costes legales sirve como incentivo para la negociación ${ }^{112}$.

\section{REFORMAS}

En las últimas dos décadas algunos parlamentos estatales norteamericanos han reformado las reglas que tratan los honorarios de los abogados. Sin embargo, no existe uniformidad sobre las normas adoptadas. Algunos estados han creado escalas móviles de honorarios, otros han impuesto un límite máximo sobre el porcentaje de la indemnización que puede corresponder a los honorarios, y por último, varios estados han instituido la posibilidad de que el tribunal revise los honorarios del abogado si no lo considera razonables.

Por ejemplo, en Illinois según los Illinois Review Statutes, capítulo 11, sección 2-1114, de 1985:

«En todas las acciones por negligencia médica, el honorario contingente total del abogado del demandante no excederá de las siguientes cantidades: (1) 33,33\% de los primeros 150.000 dólares de la indemnización; (2) 25\% de los siguientes 850.000 dólares; (3) 20\% de cualquier cantidad que supere el millón de dólares.»

En Idaho (Idaho Code 39-4213, 1975) se optó por establecer un porcentaje máximo:

«En el caso de un demandante que solicite indemnización por lesiones médicas firme un contrato contingent fee con su abogado, los honorarios iguales o superiores al $40 \%$ de la cantidad indemnizada se presumirá que son irrazonables.»

Una medida similar fue la adoptada en Florida (Florida Statutes 766.207.209, 1988):

112 El análisis realizado por Posner y por Shavell fue duramente contestado en el comentario de Harvard Law Review (vol. 104, 1990-91, p. 1.119) alegando que este razonamiento estaba equivocado porque no se había tenido en cuenta el Teorema de Coase. Según este último artículo una correcta aplicación del Teorema de Coase al modelo de Posner y Shavell revelaría que las partes tomarían las mismas decisiones en relación a la negociación extrajudicial, tanto bajo una regla como bajo la otra. 
«Cuando las partes de una demanda por negligencia médica han acordado voluntariamente el arbitraje, los honorarios del abogado del demandante y otros costes no excederán del $15 \%$ de la indemnización. Cuando el demandante ha rechazado la oferta de arbitraje, los honorarios de su abogado no excederán del 25\% de la indemnización.»

Por último, en Hawai encontramos el ejemplo de un Estado que ha optado por permitir que sea el tribunal el que determine si los honorarios son razonables o no (Hawaii Review Statutes 607-15.5 (1986)):

«En todas las acciones de daños en las que se emita una sentencia por el tribunal, los honorarios de los abogados del demandante y del demandado deberán limitarse a una cantidad razonable aprobada por el tribunal.»

La reforma de los contingent fees no se ha aceptado de forma pacífica, y ha sido sometida a recursos de inconstitucionalidad. La mayoría de estos recursos han fallado a favor de la constitucionalidad de la reforma. En Bernier v. Burris ${ }^{113}$, el Tribunal Supremo de lllinois declaró la constitucionalidad de la ley que creaba límites sobre los honorarios de los abogados. En opinión del Tribunal, el Parlamento de Illinois no había interferido en la autoridad del tribunal de supervisar los acuerdos contingentes, ya que la ley permite a éste establecer un honorario mayor en los casos en los que se considere apropiado. 